\title{
EL CONCEPTO DE MAESTRO EN ACCIÓN CULTURAL POPULAR ${ }^{1}$
}

\author{
Mgs. Luis Abrahán Sarmiento Moreno \\ Universidad Nacional Abierta y a Distancia \\ Grupo de Investigación HISULA \\ luis.sarmiento@unad.edu.co
}

Recepción: 10/09/2009

Evaluación: 07/10/2009

Aceptación: 30/10/2009

Artículo de Reflexión

\section{RESUMEN}

Acción Cultural Popular es una experiencia educativa que desde 1947 en Colombia, lleva "escuela" a los campesinos y a otros excluidos; implica el hogar y la sociedad. Esta dinámica relación: "escuela", familia y comunidad, apuntalada en el uso sistemático y combinado de las tecnologías y los medios de comunicación social, produce intuiciones importantes para el desarrollo de la humanidad: educación permanente, educación para la vida, educación integral, educación abierta, educación a distancia, educación para todos, aprendizaje autónomo y educación participativa.

Este hecho histórico - pedagógico, es posible gracias a que renovados agentes educativos intervienen en los procesos. De ahí surge la necesidad de analizar el concepto de maestro en Acción Cultural Popular. Para responder a este objetivo, siguiendo el camino de la historia social y de las ideas se ha hecho una amplia lectura de fuentes primarias y secundarias y se ha dialogado con personas implicadas en la experiencia. Se encuadra en una investigación que pretende dar cuenta de los presupuestos pedagógicos que subyacen en la universidad abierta y a distancia en Colombia.

\footnotetext{
1 Artículo presentado en el Simposio de Educadores Latinoamericanos, en el marco del VII Congreso Internacional de la Sociedad de Historia de la Universidad Latinoamericana, Sao Paulo (Brasil), agosto de 2009.

2 Candidato a Doctor en Ciencias de la Educación - RUDECOLOMBIA, Magíster en Historia, Especialista en Ética y Pedagogía, Licenciado en Filosofía y Profesional en Teología. Autor del libro ACPO, una experiencia educativa: desarrollo integral de la humanidad y de varios artículos publicados en Colombia Brasil y España, miembro del Grupos de Investigación Prospectivos y Estratégicos (GIEPE) y Líder de la Línea de Investigación Historia y Prospectiva de la Educación Abierta y a Distancia de la UNAD, y del grupo Historia y Prospectiva de la Universidad latinoamericana HISULA.
} 
Este instrumento descriptivo invita a historiadores de la educación, pedagogos y comunidad académica a una deliberación, si acaso, encontramos el matiz del concepto de "Tutor" que imprime carácter particular a la educación abierta y a distancia: un cuerpo colegiado que prepara el material, un experto en su disciplina, y en las mediaciones contexto - tecno - pedagógicas y un voluntario compañero de búsquedas y encuentros de aquellos que autónomamente asumen su propio desarrollo y el de sus comunidades.

Palabras clave: Maestro Rural - Campesino, Inclusión Social, Medios y Mediaciones en Pedagogía

\title{
THE ROLE OF A TEACHER IN POPULAR CULTURAL ACTION
}

\author{
Mgs. Luis Abrahán Sarmiento Moreno \\ Universidad Nacional Abierta y a Distancia \\ HISULA Research Group \\ luis.sarmiento@unad.edu.co
}

\begin{abstract}
Popular Cultural Action (PCA) is an educational experience that brings school to households and other marginalized groups, involving family and community. This dynamic relationship: school, family and society, coupled and combined with the systematic use, technologies and social mass media produces as a result important insights for the development of humanity: education, education for life, open education, distance education, education for all, mediated teaching, independent learning and participatory education.

This perception implies to replace a single and closed curriculum for programs that respond to the reality and pay attention to participants' social interests; to change student's anxiety into another purpose in which the student is treated as responsible for his own learning. The teacher assumes a cooperative role to accompany the learner's integral development achievement. Anew pedagogical fact is possible inasmuch as renewed agents are involved in the processes. Hence a question arises: What is the teacher's role in Popular Cultural Action? To answer this question, broad reading of primary and secondary sources has been done and discussion with people involved in the educational process has been carried out as well.
\end{abstract}

Key words: Teacher: Rural, Social Inclusion, Media and Mediation in Education. 


\section{INTRODUCCIÓN}

Acción Cultural Popular, ${ }^{3}$ al pararse sobre dos principios: "el subdesarrollo está en la mente del hombre" y "cada persona por su dignidad de hijo de Dios, está llamada y es capaz de lograr su propio desarrollo y ayudar al desarrollo de los demás". Logra capacitar a miles de líderes, quienes entre otras cosas organizan las juntas de acción comunal, en y con sus comunidades mejoraron miles de viviendas, caminos, carreteras, escuelas, puentes, parques, plazas, iglesias, fosos de abono, fogones en alto, cultivos tecnificados, explotaciones pecuarias, acueductos entre muchas otras realizaciones. Sin embargo, lo más importante, fue el ofrecer al hombre herramientas y recursos que le permitieran transformar su mente y le capacitaran para el desarrollo integral. La acogida en el proceso formativo de los medios de acción y el giro epistemológico entre alumno y "escuela" en el cual ya no es el primero el que tiene que ir a la segunda, implica reemplazar un currículo único y cerrado por programas que respondan a la realidad e interés social de los participantes; cambiar la tensión profesor alumno por una propuesta en la que el estudiante es tratado como responsable del aprendizaje; y, el maestro asume mayor compromiso en cuanto que clarifica su papel de "cultor" del desarrollo integral. Este quehacer pedagógico se afirma como un hecho democrático, al cambiar la postura de una escuela excluyente y elitista por educación para todos. Los efectivos resultados nos llevan a pensar que Acción Cultural Popular (ACPO) es una de las experiencias más significativas de educación no formal, abierta, a distancia e inclusión en la Colombia de la segunda mitad del siglo XX.

La acción cultural popular se lleva a cabo prioritariamente en los ambientes campesinos por eso, este artículo en un primer momento refleja al maestro rural que pide ser reivindicado, es decir: reconocido, valorado, capacitado y dignificado como catalizador que es del desarrollo personal y social. Un segundo segmento, retoma tres posibles figuras de "maestro": 1) El maestro comunitario, investigador y científico: capaz de leer la realidad desde el mundo de la ciencia y entender la ciencia desde el mundo de la vida; 2) El profesor locutor caracterizado por una triple especialización: en su propia disciplina, en la vida campesina y en la capacidad comunicante; 3) El auxiliar Inmediato, que encierra en si mismo tres novedades, en cuanto a su sentido de mística, voluntariedad y compromiso con su propio desarrollo y el de su comunidad. Tutor cercano, conocedor del ambiente y de la realidad de los educandos.

\footnotetext{
3 Acción Cultural Popular (ACPO) Institución fundada por Monseñor José Joaquín Salcedo Guarín, en el año de 1947 en Sutatenza Boyacá Colombia. Pretendía mediante el uso combinado y sistemático de la radio y demás Medios de Comunicación llevar educación y cultura a los campesinos dispersos en las montañas colombianas. En cuanto a contenidos cinco eran los fundamentales: Espiritualidad, Salud - Bienestar, Economía - Trabajo, Alfabeto - Comunicación y Número - Razón. Esta experiencia rápidamente muestra excelentes resultados en todas las regiones de Colombia, lo que llevó a que se replicara en otros países del mundo.
} 


\section{Maestro, Entre Luces y Sombras \\ Desde Acción Cultural Popular (ACPO) una mirada a las falencias}

La historia de la humanidad tiene que reconocer que pocas veces ha cuidado la formación de sus maestros, durante muchos años y en distintas culturas ha bastado con saber leer y escribir, Según lo cuenta ACPO, parece que los docentes no solamente estaban ejerciendo este oficio, sin preparación, sino lo que es más grave, sin vocación. Para muchos esta era una oportunidad de "realizar una tarea suave", de recibir ingresos para sobrevivir y de tener "prestigio".

En Acción Cultural Popular, había claridad en torno a que el maestro ha venido perdiendo prestigio en la sociedad, "en Colombia no se aprecia cómo debe ser al maestro de escuela. Se cree que es un ser fracasado en la vida, que se dedicó a enseñar para ganar con que comer." Esta es la queja que se registra en el primer número del periódico "El Campesino ${ }^{5}$ "; sin embargo, como ya se afirmo, es consciente que muchos maestros estaban ejerciendo este oficio sin preparación; las cifras que presenta el informe del padre Lebret, son contundentes: El $56 \%$ tiene una insuficiente base cultural y carece totalmente de formación profesional. El 13.6\% posee el título de bachiller u otro de nivel secundario, lo cual parece garantizar su base cultural, aunque no la pedagogía; y solamente el $9.7 \%$ han cursado estudios complementarios en Normales Elementales y el $2.7 \%$ en normales superiores. ${ }^{6}$

Dice en otros apartes el periódico el campesino: "Colombia es un país de agricultores que no saben agricultura... Los habitantes de los campos no han sentido la acción científica de la escuela primaria sobre los alumnos y sobre los padres de familia" "Lo cierto es que el hombre del campo ignora desde la ley elemental de la selección de la semilla hasta las triviales nociones de calcular el costo de sus productos y del cultivo de la tierra" ". La lectura que se hace en el año de 1958, parece vigente 50 años después, al ver las actuales políticas de cobertura y estándares implementados por el gobierno colombiano.

Saber cuántos son los alumnos de los centros de educación rural y cuántos niños en edad escolar dejan de asistir a las clases, ya es dato revelador. Pero analizar hasta qué punto es eficaz la educación y si realmente esta se orienta al medio, es aún más importante. El hecho es que muchos de nuestros

4 El Campesino. La voz del educador (1958 junio 29). No. 1.

5 Periódico Fundado por Acción Cultural Popular el 29 de junio de 1958; el primero que se hace para el servicio del agro colombiano, en su época era uno de los de más amplia circulación en el país y el único que llegaba hasta los rincones más apartados de Colombia. Al igual que los demás medios de acción de ACPO, era de corte pedagógico, con miras a cumplir los fines de la Institución.

6 El Campesino. El magisterio (1960, septiembre 4). No 114.

7 El Campesino. En la vida rural la renovación se impone (1958, julio 20). No. 4.

8 Sabogal, J. Diciendo y haciendo, en El Campesino. (1959, noviembre 15) No. 73. 
campesinos, después de asistir a la escuela primaria, - leen sin entender, emplean recursos intuitivos para hacer sus cuentas y no saben distinguir entre la buena y mala semilla. Han sido sometidos a una disciplina de clases limitadas, a lecciones de ortografia y aritmética complicada, con un proceso intelectual de mecanización de la enseñanza, sin trascendencia. ${ }^{9}$

Dos semanas más tarde, este mismo periódico afirma: maestros y discípulos en dificultades muy serias. Los primeros no estaban preparados para el delicado y altísimo oficio de estructurar toda una mentalidad de esos alumnos y las gentes de las vecindades. Y los segundos no fueron preparados para la vida rural científica, técnica, culta." ${ }^{10}$

Da la impresión que los dirigentes de nuestra educación no hubieran comprendido el significado de estas palabras: preparar al hombre para la vida, y solamente hubieran entendido por educación, enseñar mecánicamente unos cuantos números y unas cuantas letras, para que los niños aprendan a sumar y a leer. Con haber conseguido esto, se ha creído haber impartido educación. Error funesto. Apenas se han sentado las bases para comenzar a educar. Queda por delante todo un camino. ${ }^{11}$

El maestro que por vocación o por obligación está dispuesto a dedicarse a la enseñanza de los más pobres en las más alejadas regiones rurales, encabeza la gama de desprestigiados. ¿Qué percepción tiene este educador entre sus colegas de la ciudad? Además la educación "tradicional" pone gran énfasis en los aspectos meramente materiales de la educación: en los edificios, en los materiales pedagógicos, así como en los programas y métodos.

Es necesidad urgente que todos nuestros sistemas y medios educacionales tomen el rumbo de la verdadera educación... Debe preparar para una vida de campo grande, optimista, con inmensas posibilidades, con futuro halagador...Se entiende que preparar para esta clase de vida es la misión del maestro o de la maestra rurales. A ellos les son encomendados los hombres y las mujeres del mañana. Ellos tienen en sus manos el potencial redentor del país...nunca podrán tener la conciencia tranquila si después de un día de clase o al final del año, descubren que solo enseñaron formalidades y no enseñaron las realidades...Grande la misión del maestro rural que ha de considerarse, no un empleado público, sino un reconstructor nacional, no un mecánico de los números y de las letras, sino un hacedor de espiritus nuevos. ${ }^{12}$

Acción Cultural Popular, afirma que la verdadera escuela es el maestro; "al que estos pobres necesitan es a una persona humana que los ame, que les lleve los beneficios

\footnotetext{
9 El Campesino. Aspectos fundamentales de la educación del país (1958, agosto 14). No. 10

10 SABOGAL, J. en El Campesino. (1958, Septiembre 14). Educación para el campo. No. 12.

11 El Campesino. Un maestro un reconstructor nacional (1959, marzo 8). No. 8.

12 Ibídem.
} 
del conocimiento y de la educación"13 . La escuela rural será tan buena como sean sus maestros.

En zonas donde la Internet aún no es siquiera una fantasía, donde las bibliotecas son esquivas, donde el fluido eléctrico está ausente y, por tanto, no puede transportar información, la única fuente distinta de conocimiento es el saber y la experiencia del maestro; de manera que los mejores y más sabios docentes deberían ser los educadores de estas regiones; a mayor aislamiento de las comunidades, profesores más capacitados y con las mayores posibilidades de capacitación. Esta ecuación en teoría debe cumplirse, pero en la práctica no es siquiera un sueño, pues los lugares aislados son cubiertos por arriesgados docentes, movidos más por la necesidad que por la vocación. ${ }^{14}$ La cruda realidad, mueve a procurar una nueva concepción de maestro, que sea capaz de responder a las angustiosas realidades de las gentes; las cuales requieren de soluciones prontas y adecuadas. Así lo ven el sociólogo Camilo Torres y Berta Corredor:

Los vecinos de Sutatenza llevaban una vida casi primitiva semejante a la de la mayoría de las gentes del agro colombiano. Trabajan sus parcelas con sistemas rudimentarios e irracionales. Por lo menos la mitad del suelo de Sutatenza había sido afectado por la erosión hasta hacerlo inútil. Los caminos dificiles e intransitables en épocas de lluvias impedian el acercamiento de las gentes. Las viviendas de bareque y paja. Mal construidas y peor conservadas constituian un peligro permanente para el bienestar de la familia. El analfabetismo era muy elevado; los habitantes no sabían leer $n i$ escribir $y$, lo que es peor no les interesaba aprender. ${ }^{15}$

El asunto parece muy elemental: "Los maestros de nuestras escuelas primarias no saben agricultura. ¿Cómo pues podrán enseñarla? No existe la planificación de la Escuela Rural hacia el campo y sobre todo nadie está convencido de formar buenos agricultores"16. Además de saber se debe querer, así es como la página editorial del citado periódico indica: "Para instruir a los niños, lo que principalmente necesita el maestro no es tan solo cabeza, sino principalmente corazón."17 Y para ACPO la solución es muy sencilla: "que las maestras y los maestros de escuela rural, dignos todos de respeto y admiración, posean esta ciencia y la sepan enseñar con la facilidad con que se camina o se ríe." 18

\footnotetext{
13 SARMIENTO MORENO, Luis Abrahán. (2009): ACPO, una experiencia educativa: desarrollo integral de la humanidad. Bogotá, Universidad Nacional Abierta y a Distancia (UNAD), p. 273.

14 SARMIENTO MORENO, Luis Abrahán. (2005): Pensamiento educativo de Monseñor José Joaquín Salcedo Guarín. Tesis de Maestría en Historia. Universidad Pedagógica y Tecnológica de Colombia (UPTC).

15 TORRES, Camilo y CORREDOR, Berta. (1961): Las escuelas radiofónicas de Sutatenza. Colombia. Universidad Nacional. Centro de investigaciones sociales serie socioeconómica No. 2. Bogotá, p. 11.

16 MONASTOQUE, J. Escuela Primaria y Agricultura, en El Campesino. (1959, Noviembre 15). No. 73.

${ }^{17}$ Ibídem, p. 39.

18 El Campesino. Educación para el campo. (1958, Septiembre 14). No. 12.
} 


\section{Algunos Sectores Aportan Luces}

Dentro del interés de dignificar y dar calidad a la labor educativa rural ACPO, plantea cómo ayudar al maestro en su formación, colijamos uno de estos propósitos: Revisar el Pénsum de las Escuelas Normales para que los maestros reciban la formación conveniente en agricultura, zootecnia, economía rural, etc., y puedan así educar a los niños campesinos. A la maestra rural hay que vincularla al campo haciéndola participe de los producidos de la granja escolar; facilitándole la adquisición de "la vaca lechera."19 Ella debe saber vacunar animales y tener en la escuela los elementos necesarios. Que la maestra sea elemento principal en la campaña de mejoramiento de la vereda y de la casa campesina, haciéndola responsable en casos de negligencia. Prepararla para la labor social que debe hacer en la vereda ${ }^{20}$.

En el sector rural y en la educación en general es fundamental la integración de todos los sectores sociales. Pero especialmente la familia y la escuela forman una llave inseparable, pues "son muy graves las responsabilidades que tienen los padres de familia respecto a la educación de sus hijos. Ellos deben proporcionar los medios para que se preparen moral e intelectualmente para enfrentarse con la vida" ${ }^{21}$. Este asunto resulta de pasmosa actualidad cincuenta años más tarde en Colombia; donde se sigue equiparando educación a escuela y el concepto de escuela sigue siendo un sistema cerrado y aislado.

Padres que envían a los hijos a la escuela y creen que con esto han cumplido la totalidad de sus obligaciones. Los abandonan a su propia suerte. Con puntualidad les proporcionan los útiles y cuanto consideran necesario para cumplir las lecciones. Pero no se preocupan por saber cual es su comportamiento en la escuela, por conocer los amigos que frecuentan, las etapas que van cumpliendo, la manera como el niño despierta a la vida y sus misterios. No tienen ningún contacto con el profesor a quien han delegado para compartir con ellos la responsabilidad de la educación de los seres que trajeron al mundo. Porque el primer educador es el padre y la primera educadora es la madre, y el maestro y la maestra solo lo son en cuanto ellos requieran su colaboración. ${ }^{22}$

En un manuscrito Monseñor Salcedo ${ }^{23}$ manifiesta su sentir sobre el maestro: Tarea realmente bella y necesaria, el docente es el agente catalizador del desarrollo. Entre los pobres de las zonas rurales no se puede educar al niño sin educar también a sus padres.

\footnotetext{
19 Una de las Campañas emprendidas por ACPO, con miras a mejorar la nutrición, la salud y la economía de la familia.

20 El Campesino. Preparación rural de los maestros. (1959, Julio 12). No. 55

21 El Campesino. Los padres de familia ante la escuela. (1959, Febrero 8). No. 33.

22 Ibídem.

23 José Joaquín Salcedo Guarín. Un hombre eminentemente práctico, nacido en Corrales Boyacá en el año de 1921, Educado en primer lugar por su madre la educadora Eva y la influencia de su padre el telegrafista José Joaquín, estudia en el Colegio Salesiano de Tunja y complementa su
} 
En las escuelas rurales de Colombia, el 90\% de los alumnos abandonaron sus estudios antes de terminarlos. En gran parte la culpa es de los adultos, de los padres, y depende de la manera de pensar de personas para las cuales la instrucción no tiene un lugar de importancia. Por eso, el maestro, que se dedica a los pobres del campo, se encuentra frente al problema de ayudarlos a concebir una nueva manera de pensar y obrar. Esta tarea exige mucha imaginación, iniciativa y un ingenio inventivo en el proceso de educar a los pobres. No es suficiente solo trasladar al medio rural los métodos educativos de la zona urbana ya desarrollada. ${ }^{24}$

Una concepción de maestro nacida en el mundo de las necesidades es necesariamente diferente a la nacida tras la comodidad de un escritorio de oficina. El maestro es un líder capaz de integrar para el educando el "mundo de la vida". La escuela deja de ser un mero lugar físico y pasa a ser la intercesión entre la familia y la sociedad. La socialización es un elemento fundamental para el mundo campesino, en razón a que este vive aislado en su parcela y con dificultad puede hacer vida social.

Todos sabemos que a partir de cierta edad los niños tienen un deseo profundo de vida social... es necesario dar a los niños en la escuela, lo más a menudo posible ocasión de cumplir este aprendizaje que la familia no puede dar cabalmente...tres son, en efecto, los pilares sobre los cuales descansa la obra educativa: hogar, escuela y sociedad. La escuela no recibe, pues la semilla. Ella es el lugar de transplante. Ella solo recibe pequeños arbolitos lozanos unos, raquíticos otros. ${ }^{25}$

El maestro debe ser el primero en cuestionar su ejercicio y en abrirse a las nuevas posibilidades, de no ser así, resultarían "Vanos los esfuerzos por desarrollar modelos propios (de democracia) en caso que fuera posible hacerlo, si no se hacen profundos replanteamientos de carácter cultural que necesariamente son educativos y no son tarea única de los educadores tradicionales. ${ }^{26}$

\footnotetext{
formación en el Seminario de Tunja, donde se encuentra con el sabio Ángel María Navia, quien influye definitivamente en su vida; después de haber hecho como seminarista el acueducto de Beteitiva y otras acciones en favor de varios pueblos de Boyacá, fue ordenado sacerdote en el año de 1947. El mismo año fue asignado como coadjutor de la parroquia de Sutatenza y ahí mismo inicia la experiencia de educación y cultura para los campesinos colombianos gracias al uso sistemático y combinado de la radio y demás Medios de Comunicación Social. A su fundación la llama Acción Cultural Popular - Escuelas Radiofónicas; experiencia que se extiende rápidamente por todo el país y pasa las fronteras llegando a ser tenida en cuenta en países asiáticos, africanos y por lo menos en 15 países de América Latina. Después de prestar un sinnúmero de servicios a la humanidad, recibir un buen número de reconocimientos y condecoraciones muere en Miami Florida en el año de 1994.

${ }^{24}$ SALCEDO GUARIN, José Joaquín. MANUSCRITO para artículos sobre ACPO. Para el periódico 'El Tiempo' (Sin más datos). Archivo Sutatenza.

${ }^{25}$ El Campesino. Orientación pedagógica. Organización del trabajo escolar por equipos. (1960, Diciembre 18). No. 129

${ }^{26}$ SALCEDO GUARIN, José Joaquín. (1994): Sin producir riqueza no se acaba la pobreza. Bogotá, Violeta. P. 39.
}

Rhela. Vol. 13. Año 2009, pp. $128-147$ 
El Ministro de Educación Nacional Reynaldo Muñoz Zambrano, también estaba convencido que "La creación de una conciencia en la sociedad colombiana de que (sic) el problema básico para nuestro destino como pueblo es la educación.”27 El principal agente en este proceso es el maestro; pero un maestro con dignidad, vocación y capacitación. "Si la situación económica y social del magisterio no se mejora, si no se consigue dar a los futuros maestros una comprensión y competencia tal que les permita ejercer, con exacto conocimiento del medio y sus posibilidades, una tarea educacional acomodada, nunca llegaremos a formalizar comunicaciones profundas y constantes entre la vida escolar y la vida nacional." ${ }^{.28}$

Parecida voz alza la Universidad Pedagógica Nacional a través de su rectora Franzisca Radke, en torno al problema de la educación campesina y del docente rural. "Debe desaparecer el criterio de que cualquiera puede ser maestro rural... La misión del maestro rural es muy exigente. El tiene que hacer amar el campo a sus alumnos para que no huyan de él buscando las candilejas de la ciudad. ${ }^{29}$

Afirma además, la necesidad de igualar los programas de la educación rural con los de la urbana, si bien dejando a la primera las materias propias de una adecuada formación y orientación agraria en los alumnos. "Por otro lado debe tenerse en cuenta que la duración de la enseñanza urbana es en la actualidad de 5 años para cada sexo. En cambio la enseñanza rural se hace en tan solo 4 años y en forma alterna... viene a quedar reducida a 2 años."

El discurso del Ministro de Educación Gabriel Betancourt Mejía, parece hacer claridad sobre el caso, sin embargo, "del dicho al hecho hay mucho trecho." ${ }^{30}$

El maestro rural tiene que darse cuenta de lo que él significa para el adelanto de la patria. Su labor cubre un campo extraordinario, pues además de los conocimientos que comparte, modela los hábitos fundamentales que determinan el éxito o el fracaso de sus educandos...debe compenetrarse con las necesidades y aspiraciones de su vereda. Ser el propulsor de obras de progreso para la comunidad. Despertar en los padres la mística por la educación de sus hijos; demostrarles que ella es el mejor capital que pueden darles y que por su medio alcanzarán un porvenir más digno. Pero es especialmente con su ejemplo como el maestro debe complementar su labor escolar. El maestro debe ser modelo de ciudadano y de padre de familia, y así entonces, su labor se extenderá con grandísimo fruto, más allá de los límites de la escuela. ${ }^{31}$

\footnotetext{
27 El Campesino. Aspectos fundamentales de la educación del país (1958, Agosto 31). No. 


\section{Una fundación puesta al servicio de la dignidad humana}

Acción Cultural Popular (ACPO), se da a la tarea de dignificar el quehacer del maestro y a través de sus medios de acción procura de una parte que los maestros rurales se capaciten y de otra que los campesinos y colombianos en general le reconozcan, aprecien y valoren:

En Colombia existe una persona de grandísima importancia: es el maestro. $Y$ es de ganadísima importancia, precisamente porque el Maestro de la Escuela Urbana o de la Escuela Rural de la vereda, es quien colabora en la educación de los hijos de los campesinos. Su trabajo merece nuestra gratitud y nuestra admiración. Tú, campesino, que estás leyendo, debes saber quién es el maestro, cuánto vale y cómo debemos ayudarlo. Defendamos a nuestros Maestros y Maestras. Estudiemos poco a poco como debe ser un Maestro, y que obligaciones tenemos los colombianos para con ellos. ${ }^{32}$

El periódico El Campesino, en la editorial del 15 de mayo de 1960, sigue la defensa, en un artículo que titula: "MAESTRO - UN TITULO DE HONOR Y DE GLORIA"

Lo primero que la nación, el gobierno y la sociedad deben hacer es colocar al maestro en el lugar que le corresponde. Tanto en lo público como en lo privado, por razón de la dignidad de su misión, al Maestro le corresponde el primer puesto de honor...

Hombres y mujeres que sientan el orgullo de su profesión. Niños que aspiren y sueñen con la gloria de ser Maestros. Jóvenes que busquen el profesorado no como el último recurso cuando se les han cerrado todos los otros, sino como la más brillante misión que un muchacho puede escoger. La misma palabra "Maestro" hay que valorizarla de tal manera que responda a la tradicional grandeza de su etimología, pues la palabra "Maestro" viene del latín "Magíster" que significa tres veces más, tres veces grandes...

Personalmente el Maestro reúne extraordinarias virtudes intelectuales y morales. Una inteligencia en continuo progreso y un corazón todo bondad. Este valor personal del Maestro constituye la tercera fuente de grandeza. Que los maestros se den cuenta de lo que son y que no se rebajen ni degraden, tanto en su vida privada como en su actividad pública, es lo que necesita la patria. El Maestro tiene que ser el modelo y el espejo de la sociedad. ${ }^{33}$

ACPO, garante de las necesidades que se presentan en la educación del campesinado, se embarca en otra empresa pionera, que abre horizontes en la preparación de maestros, especialmente formados para ser educadores de la escuela campesina. Así lo plantea en su informe el Director General de ACPO:

\footnotetext{
32 El Campesino. La voz del educador. (1958, Junio 29). No. 1

33 Ibídem.
} 
Indudablemente, es esta la primera experiencia en el mundo de organización de una normal radial. Según la estadística que lleva el Ministerio de Educación Nacional, reuniendo los datos aportados por las direcciones departamentales de educación, siguen los cursos que se transmiten por la emisora de Sutatenza 5.733 maestros esparcidos por todo el País. Los programas se emiten dos veces al día, para facilitar su sintonía a los maestros; tanto el plan de enseñanza como el desarrollo de las lecciones, están a cargo de profesores designados por el Ministerio, que proporciona los materiales complementarios y tiene la totalidad de la responsabilidad técnica y pedagógica de los cursos. ${ }^{34}$

Leamos el testimonio del profesor Solarte

ACPO no solo está trabajando con el único fin de beneficiar al campesinado colombiano sino también para proporcionar su eficacísima ayuda al magisterio colombiano, y yo soy uno de los primeros maestros que, comprendiendo a fondo la eficiencia pedagógica de los dignísimos y venerables profesores de las Escuelas Radiofónicas de Sutatenza, he comenzado por llevar a mis aulas las sabias y preciosas enseñanzas que se dictan en Sutatenza. ${ }^{35}$

Estos Cursos por radio para docentes llegan a ser muy exitosos como puede verse en el periódico El Campesino número 9, de agosto 24 de 1958: "pueden ingresar todos los maestros oficiales de enseñanza primaria - escalafonados o no a excepción de los graduados en normales superiores. Las matrículas o inscripciones, son atendidas actualmente en todas las secretarias de educación del país... [Los cursos] se harán por correspondencia, por emisiones radiales y por enseñanza directa."

Otra contribución que Acción Cultural Popular, hace en favor del maestro y la educación rural es la implementación del proyecto de "Biblioteca del Campesino"36 Teniendo en cuenta que "La elaboración de una biblioteca en las escuelas rurales como centro de consulta e información, constituye indiscutiblemente un aporte decisivo para los jóvenes escolares campesinos, que podrán derivar de ellas valiosas enseñanzas sobre los diversos sistemas de cultivo, enfermedades, procedimientos, etc. Al mismo tiempo que la formación de una cultura vital para su futuro." ${ }^{37}$

\footnotetext{
34 SALCEDO GUARÍN, José Joaquín. (1957): Las Escuelas Radiofónicas y su labor de 1954 a 1957. Informe de la dirección general de Acción Cultural Popular - Escuelas Radiofónicas a la II Asamblea General de la institución. Archivo Sutatenza, p 50.

35 SOLARTE, José. (1954): Carta enviada desde Chenkayb Santa Ana Nariño, en Radio Sutatenza. Boletín de programas para las escuelas radiofónicas y los hogares colombianos. No. 12. (Agosto de 1954).

36 Otro de los medios de acción de ACPO; El campesino que aprendía a leer, debía tener material para la lectura el periódico no era suficiente. Se trata de una serie de colecciones, al menos 100 títulos sobre variados temas de interés.

37 El Campesino. Como hacer la biblioteca rural. (1958, Agosto 17). No. 8.
} 
En la práctica el mayor número de volúmenes que conformaban la biblioteca de las veredas eran los de la colección de la "Biblioteca del Campesino". Y a través del periódico constantemente da orientaciones sobre: "Normas, Temas, Selección, Publicaciones, Clasificación y Grupos especiales." 38 Además en el periódico El Campesino con gráficos ilustra y enseña como elaborar los distintos muebles para biblioteca.

ACPO insiste en que el maestro debe ser consciente que el educando no es "tabula raza," sino que reconozca en el estudiante saberes previos y experiencias aprendidas en el "mundo de la vida;" además debe tener mirada aguda para poder tener en cuenta "las aptitudes de los niños para determinadas labores y artes... el maestro debe estudiarlo y comprenderlo... cuántos de nuestros hombres, que en un comienzo manifestaron determinadas aptitudes, han fracasado a la postre por la falta de una adecuada orientación." ${ }^{39}$

Otro aporte curioso para la humanidad logró resultar de las conversaciones entre Mario Moreno "Cantinflas" y José Joaquín Salcedo Guarín "El Quijote" son dos películas, realizadas por el comediante pero inspiradas en las ideas del "soñador": "le dijo a Mario que sus películas estaban muy cerca del pueblo porque lo hacían reír mucho, que en este sentido él era un verdadero líder y que ante la necesidad de motivar al pueblo para que se alfabetizara sería maravilloso que hicieran una película que contribuyera a una mayor alfabetización. Mario, con su gran agilidad mental, consintió a hacerla...El Analfabeta" ${ }^{40}$. La segunda en referencia es la ampliamente conocida "El Profe".

Vale la pena ahora, reconocer la labor, desde un comentario del Padre José Ramón Sabogal:

En la historia patria no se cuenta que los campesinos se hubieran dado en alguna época a la tarea de enseñar, de ser maestros, de buscar a las otras personas campesinas para participarles su bien, para repartirles de su tesoro ¡ahora sí! Las Escuelas Radiofónicas son de los campesinos... Nosotros no reclamamos nuestros derechos sino que nos reclamamos a nosotros mismos los deberes que tenemos para con quienes están más pobres que nosotros; y por eso les estamos llevando la riqueza de la lectura, les estamos dando con cariño de lo que tenemos...la pedagogía de la caridad está haciendo la historia de la cultura campesina del país. ${ }^{41}$

Acción Cultural Popular, es entonces una suma de voluntades campesinas que se sienten responsables de su propia educación y de la educación de los conciudadanos; de su propio desarrollo y del desarrollo integral de la humanidad. Son acciones contextuadas en lo rural.

\footnotetext{
${ }^{38}$ Ibídem.

39 El Campesino. Las aptitudes. (1960, Febrero 14). No. 85

40 ZALAMEA Luis. (1994): Un Quijote Visionario, Jorge Plazas. Bogotá, Presencia, p. 145.

${ }^{41}$ SABOGAl J. Diciendo y haciendo, en El Campesino. (1959, Julio 12). No. 55.
} 


\section{El maestro al interior de Acción Cultural Popular (ACPO)}

La figura del maestro al interior de Acción Cultural Popular, responde al pensamiento descrito anteriormente, pero adicionalmente se cataloga en varios órdenes, todos fundamentales en el quehacer educativo de la institución.

\section{El Maestro Investigador:}

Es el científico, generalmente es un colectivo que tiene como principal tarea la elaboración de materiales educativos. Material que debía ser cuidadosamente preparado; así lo reconocen expertos internacionales:

El contenido del programa para cada curso anual es planeado con bastante anterioridad al primer programa del año. La preparación de los elementos pedagógicos (con excepción del contenido de enseñanza religiosa) es responsabilidad de un equipo de doce profesores, calificados en enseñanza y especializados en las asignaturas de estudio. El mismo equipo de profesores fue también ampliamente responsable de la preparación de la serie de textos (cartillas). Las clases radiales son preparadas nuevamente cada año, permitiendo así revisiones periódicas del material. ${ }^{42}$

Sin duda otra destreza metodológica resultante de la delicada preparación es la combinación de estrategias y recursos, para lograr aprendizajes y resultados prácticos. He aquí un ejemplo, como lo plantea el investigador Stephan Brumberg.

Si la campaña semanal se refiere a la construcción de pisos en las casas las clases radiales sobre la salud podrían incluir información sobre los beneficiarios en salud de tener pisos en las casas, las clases radiales de matemáticas podría intervenir en la medición de áreas, la clase dedicada a campañas trataría algunos de los aspectos técnicos de la construcción de pisos y el periódico llevaría ilustraciones de procedimientos a seguir, los trabajadores locales de ACPO (líderes locales, auxiliares y dirigentes) tratarían de promover la construcción de pisos proporcionando la asistencia técnica que ellos pueden e informarían anticipadamente a los participantes sobre cómo y dónde obtener los materiales de construcción requeridos. ${ }^{43}$

\section{Profesor Locutor}

Son maestros altamente capacitados que deben responder a varias condiciones: Expertos en el área de su conocimiento, con una vasta formación pedagógica, expertos conocedores de la vida del campo y hábiles comunicadores a través de la radio y los demás medios de comunicación social. Así, los presenta la 'Guía introductoria para el conocimiento de ACPO

\footnotetext{
42 BRUMBERG, Stephan. (1978): Los medios masivos de comunicación al servicio del desarrollo rural colombiano, en Teoría y aplicación en el caso de Acción Cultural Popular. BERNAL ALARCÓN, Hernando. Bogotá, Andes. p. 64.

43 BRUMBERG, Stephan. (1978): Op. Cit, p. 18.
} 
Luis Abranán Sarmiento

Uno de los secretos del éxito de un profesor que hable por la radio es el lograr que su comunicación sea lo más personal posible. Que el grupo radiofónico sienta que al prender la radio llega un amigo a sentarse a dialogar con ellos. Para esto, es necesario que el profesor tenga un gran conocimiento de la vida campesina, y que en el momento de grabar las clases sea capaz de reproducir en su imaginación las circunstancias de sus oyentes, las clases de Escuela Radiofónica tiene que 'sonar' distinto a un noticiero o a un partido de football (...); se requiere un trato personal. La clase no se oye, sino se escucha. ${ }^{44}$

Otra razón que lleva a tener un especial cuidado pedagógico, continúa diciendo Monseñor Salcedo Guarín es que:

El profesor locutor, es un profesor ciego, no ve a los alumnos y es sordo, no puede oír a sus alumnos - sus preguntas - Los alumnos son mudos, no le pueden preguntar al profesor y también son ciegos, no lo ven. Estos son dos graves problemas del profesor y de los alumnos, que deben hasta donde sea posible, superarse por la metodología y sobre todo por la grafica precisa, a la insinuación a través de la cartilla o del cuaderno o la lámina que permita suplir en buena parte ese defecto grave de la radiodifusión. ${ }^{45}$

Para superar las limitantes del sistema se cuenta con el ingenio y con herramientas tales como "La correspondencia": "la cual fue el primer tipo de repuesta que recibieron los profesores de la Acción Cultural Popular y el primer estímulo a su acción educadora transmitida desde lejos, valiéndose de la radio." ${ }^{\text {46 }}$ Con la ayuda del documento Principios y Fundamentos Teóricos, de Acción Cultural Popular ${ }^{47}$ se encuentran cuatro conceptos propios de este proceso pedagógico: reflexión, diálogo, participación y práctica.

El auxiliar y los miembros del grupo radiofónico deben dialogar entre ellos. Comentar y comunicar las propias impresiones, saber escuchar a los demás es importantísimo en la metodología de la Educación Fundamental Integral, pues, es la forma de hacer crecer el sentido humano y lograr la cohesión de las "Escuelas Radiofónicas ${ }^{48}$ "

\footnotetext{
44 ACCIÓN CULTURAL POPULAR. (1979): Sus principios y medios de acción. Consideraciones Teológicas y Sociológicas. Bogotá, Andes. Archivo Sutatenza, pp. 29 - 30.

${ }^{45}$ Ibídem, p. 30

46 SALCEDO GUARÍN, José Joaquín. Las Cartillas un elemento de acción y un medio de comunicación de Acción Cultural Popular. Legajo: Documentos de Consulta para la historia de Acción Cultural Popular. Documento (3) s. f., p. 4.

47 ACCIÓN CULTURAL POPULAR. (1977): Principios y fundamentos teóricos. Guía introductoria al conocimiento de ACPO. Bogotá: Andes. Archivo Sutatenza, p. 57.

${ }^{48}$ Es el nombre que asume el grupo humano que se reúne en torno al receptor; coordinado por el Auxiliar Inmediato, para con la ayuda del tablero, la tiza, las láminas, los libros de la biblioteca, el periódico, las cintas magnetofónicas y los demás medios de acción adelantan el autoaprendizaje en un ambiente de libertad y responsabilidad.
} 


\section{El Auxiliar Inmediato}

Es una genial creación de ACPO, sin el cual, no podría realizar sus fines. "Un apóstol seglar de alma generosa, dispuesto por el espíritu y convicción de verdadero cristiano, a servir al prójimo. Un compañero de los demás alumnos que, durante la clase se convierte en maestro con el sólo hecho de obedecer al pie de la letra las sencillas órdenes del profesor - locutor." ${ }^{\prime 4}$

El auxiliar inmediato, se educa y ayuda a educar, realiza personalmente y para los demás el mejoramiento económico, social y cultural. El grupo de auxiliares; colabora eficazmente con la comunidad, dentro de su ambiente." ${ }^{50}$ Es en esta figura donde mejor podemos ver el sentido de responsabilidad y caridad mundial a la que refería el Padre Ramón Sabogal; pues es un adalid que dirigido por el profesor - locutor, logra hacer objetiva - por medio del tablero, la cartilla y las láminas la enseñanza auditiva que reciben los alumnos. "Un auxiliar - alumno, que junto con los compañeros de clase aprende y adelanta en conocimientos, a medida que ayuda a trasmitirles las nociones de las materias enseñadas." ${ }^{51}$

Es el alma de la Escuela Radiofónica, "La selección del auxiliar se hace de diversas maneras. Algunas veces es seleccionado por el grupo que desea participar como escuela radiofónica. También ocurre que el organiza el grupo e inicialmente asume la función de auxiliar. En otros casos, el líder, el dirigente, o el párroco lo seleccionan." ${ }^{52} \mathrm{El}$ Auxiliar Inmediato es quien matricula y anota en las planillas a los campesinos; quien envía cada mes, con el visto bueno del señor cura párroco, la lista de asistencia de sus alumnos; el que enciende el receptor todos los días a la hora de la clase y da la llamada oportuna por medio del riel. Al empezar la clase está listo al calor del receptor para ejecutar las órdenes que da el profesor locutor desde Sutatenza. Está listo para orientar a los alumnos sobre aquello que deben repetir, escribir, leer o hacer. "Es la conexión, el eslabón entre la emisora de la Iglesia y los campesinos." ${ }^{53}$

Monseñor Salcedo a los auxiliares inmediatos les da libertad y les colabora para llevar adelante las pequeñas y grandes iniciativas, con tal que no pierdan de vista la meta: educar integralmente al campesino, así son las cuestiones:

¿Quién los llama al servicio de sus hermanos campesinos como auxiliares inmediatos? ¿Por qué trabajan en esta obra? ¿Cuál es la recompensa que esperan de sus desveladas preocupaciones y, aun molestias? Actualmente Dios ha deparado muchos miles de campesinos o auxiliares inmediatos que

\footnotetext{
49 El Campesino. El auxiliar Inmediato. (1960, Junio 12). No. 102.

${ }^{50}$ ACCIÓN CULTURAL POPULAR. (1979): Sus principios y medios de acción.

Consideraciones Teológicas y Sociológicas, Bogotá, Andes. Archivo Sutatenza, p. 6.

${ }^{51}$ Ibídem,p.7

${ }^{52}$ MORGAN Robert; MUHLMAN Liliana y MASONER Paúl. (1980): Evaluación de sistemas de comunicación educativa. Bogotá, Andes, p. 54.

${ }^{53}$ SABOGAL José Ramón. Las Escuelas Radiofónicas, en Escuelas Radiofónicas Acción Cultural Popular. VARGAZ, Carlos, p. 12.
} 
son la clave de la enseñanza a través de la radio. Quiero dejar, en esta oportunidad, una idea muy clara como base inconmovible de la verdadera formación de auxiliares inmediatos: es la caridad cristiana, la mística católica, que es el amor al prójimo por el bien de nuestras propias almas. ${ }^{54}$

Muy rápidamente se da cuenta del papel que cumple en la estructura cultural, y procura cuidar para ellos todos los detalles: "El auxiliar debe darse cuenta de que (sic) es indispensable la organización (....) y recuerde: nada desorganizado dará frutos ni prestará servicios. Nada desorganizado podrá ser índice de una actividad constante. Necesitamos Escuelas Radiofónicas organizadas y esta organización está en manos de los auxiliares inmediatos ${ }^{55}$. La exigencia hacia ellos cumple doble tarea: de una parte, el Auxiliar Inmediato es el primero en sacarle provecho a la educación, y de otra, un buen Auxiliar Inmediato es la garantía para tener una buena Escuela Radiofónica. "Tiene que ser maestro en todo: maestro en la virtud, maestro en el cumplimiento del deber, maestro en la responsabilidad, maestro en el buen obrar, en el buen pensar; en la conversación y en fin en todo aquello que sea para la mayor gloria de Dios. ${ }^{56}$

Hay que decir que ACPO, no descubrió la utilización de la radio, ni que por primera vez en el mundo utilizó las ondas hertzianas para multiplicar la acción, dice Salcedo.

Pero si sostengo que la radiodifusión se halla ahora organizada de manera tal que un profesor-locutor habla desde la emisora y un ilustre y benemérito ciudadano sigue sus instrucciones a muchos centenares de kilómetros de distancia y realiza esa preciosa tarea como Auxiliar Inmediato y esto si sucede ahora por primera vez en la historia (...) Nunca en la historia se había dedicado una emisora y una organización exclusivamente a utilizar este proceso. ${ }^{57}$

\section{Maestros de las Pedagogías Mediadas}

Sin duda que la modalidad pedagógica inaugurada en Colombia en 1947, plantea nuevos retos para el maestro, los mismos que hoy estamos viendo. Un verdadero compromiso de quienes son responsables de la educación y por lo tanto los primeros llamados a fraguar este cambio mental porque poseen los recursos y la capacidad para hacerlo. Así es el planteamiento de Monseñor Salcedo Guarín:

\footnotetext{
${ }^{54}$ SALCEDO GUARÍN, José Joaquín. (1957): Introducción, en Orientaciones para dirigentes campesinos de Escuelas Radiofónica. CASTRO, Siervo Tulio. (Coordinador), Sutatenza Instituto Masculino, Mimeografiado. Archivo Sutatenza. p. 10.

55 SALCEDO GUARÍN, José Joaquín. (1956): Normas especiales para los auxiliares inmediatos. ACPO Escuelas Radiofónicas. Sutatenza Boyacá Colombia. Pío X. Archivo Sutatenza. p. 12.

56 Ibídem, p. 2.

${ }^{57}$ SALCEDO GUARÍN José Joaquín. (1955): Auxiliares inmediatos, en Boletín de programas para las Escuelas Radiofónicas y para los hogares colombianos No 20. BERNAL ESCOBAR, Luis. (Director) Sutatenza, Archivo Sutatenza. p. 10.
} 
La irrupción de los medios en los procesos de enseñanza-aprendizaje implica que el maestro asuma nuevos roles. De ninguna manera se llegará a la situación que algunos temen de que desaparezca el maestro. Ciertamente se cambia la figura del maestro tradicional, como se han cambiado los roles de múltiples profesionales, sin que esto implique que se eliminen las profesiones como tales en la época de la información; los maestros dejan de ser los únicos transmisores del saber y el conocer, para convertirse también en guias, en orientadores, en motivadores, en impulsores, funciones todas que siempre les han pertenecido, pero que anteriormente eran subsidiarias a su labor primordial de enseñar en el salón de clase. Los contenidos para los medios no podrán realizarse, sin maestros, profesores y científicos.

El maestro tiene no solo que enseñar directamente a los estudiantes en el aula, sino que debe aprender las tecnologías educativas que le permitan diseñar materiales, someterlos a prueba, perfeccionarlos, desarrollar sistemas de autoevaluación, vigilar y controlar procesos de aprendizaje individual, administrar sistemas de evaluación académica en términos amplios y masivos, construir bancos de preguntas, preparar materiales para aprendizaje auxiliado por el computador; utilizar el mismo computador tanto en sistemas de enseñanza como en proceso de administración educativa, lograr una mejor utilización del tiempo y los espacios escolares; diseñar, probar y evaluar nuevos currículos educativos. ${ }^{58}$

El Maestro que educa mediante el uso combinado de los medios de comunicación social, logra una educación básica y extensiva, llega "a todos los sectores de la población y principalmente a los marginados, no requiere de las cuatro paredes de una escuela, ni de la presencia de profesores permanentes salidos de las normales o de las facultades de educación" 59 . Se genera educación abierta, orientada hacia la solución de los problemas propios de la personas y con la participación organizada de los propios beneficiarios.

"La utilización de los medios en ACPO resulta ser la gran novedad pedagógica; sin embargo, son solo eso: 'medios'. Lo fundamental son las personas." ${ }^{\prime 60}$ Por eso, en Acción Cultural Popular, los auxiliares inmediatos, los líderes, supervisores, profesores, locutores y demás personal de acción son el elemento fundamental en esta tarea pedagógica. ${ }^{61}$

\footnotetext{
${ }^{58}$ SALCEDO GUARÍN, José Joaquín; BERNAL ALARCON Hernando e IGLESIAS Nohora Inés. (1990): América latina la revolución de la esperanza. Bogotá, Violeta, pp. 219 - 220.

${ }^{59}$ BERNAL ALARCON, Hernando. (1994): ACPO Una idea con semilla de futuro. Escrito a raíz de la Muerte de Monseñor Salcedo, p. 15.

${ }^{60}$ SARMIENTO. (2005): Op. Cit, p. 171.

${ }^{61}$ Inicialmente escrito como ponencia para el VII Congresso internacional da sociedade de história da educaçâo latinoamericana Sao Paulo - Brasil. agosto de 2009.
} 


\section{CONCLUSIONES}

Acción Cultural Popular, comparte que la educación es el elemento fundamental para el desarrollo integral de los individuos y de la sociedad. Siguiendo la Doctrina Social de la Iglesia, se muestra consiente que con educación todo se logra y sin ella todo es perdido. Podemos entrever un nuevo concepto de aprendizaje, como derecho y deber de todos, como un hecho libre y responsable, autónomo y comprometido con los procesos sociales. Se da cuenta de la incapacidad práctica que tiene el estado para poder llevar el ideal de educación a todos los ciudadanos, pero no se estanca en la crítica ni se queda solamente en los paliativos, sino que movido por la dura realidad circundante se da a la tarea de realizar una "acción cultural popular". Lo que hay que hacer es asunto claro, el problema está en cómo realizarlo. La respuesta a esta pregunta genera un nuevo movimiento pedagógico que en la práctica se hace capaz de superar las limitantes de distancias, carencias de recursos, incapacidad y escasez de maestros. La genialidad inicia con la introducción de la radio y los demás medios de comunicación social vigentes en la época, en los procesos educativos.

La novedad está en el uso sistemático y combinado de los Medios de acción, dinamizados por agentes interpersonales. La capacidad de organizar la emisión llenándola de contenidos decididamente preparados por expertos científicos yhábilmente transmitidos por "Profesores Locutores" llegando a los más impensados rincones de la geografía colombiana. La primicia está en la organización de la recepción liderada por un auxiliar inmediato que se convierte en la extensión, en la presencia del maestro que habla por la radio. Y la manera como el grupo humano receptor que en este caso se llama Escuela Radiofónica, hace vida el mensaje en la cotidianidad de su vereda. Se pasa de un devaluado concepto de maestro rural carente, al de capital humano: tres figuras de "maestro": el maestro investigador y creador, el profesor locutor y el auxiliar inmediato.

Al dejar ver las falencias del "maestro tradicional", se propone un nuevo concepto de "maestro", un maestro dignificado y capacitado, capaz de utilizar los adelantos del mundo moderno y de asumir nuevos roles sociales, un maestro cercano, conocedor del mundo de la vida del estudiante, un maestro dinámico y dinamizador de procesos, un maestro que se distancia de la repetición y el quietismo y se lanza a la aventura de la creatividad y la acción. El maestro es entonces el encargado de derribar las fronteras de la escuela y hacer que sus límites se extiendan hasta el hogar: la cocina con fogón en alto, la huerta casera, el foso de abono, la plaza de mercado, el establo, la casa campesina, el teatro, el hospital y el templo parroquial. A su vez por las elásticas paredes de la escuela puede pasar el mundo de la vida de cada uno de los miembros de la familia.

El maestro deja de ser el potenciador de una parte del tiempo del alumno y se convierte en el dinamizador de la vida del estudiante. Es un "magíster", en cuanto que procura el triple crecimiento: su desarrollo personal, progresión del alumno y perfeccionamiento de la sociedad. Recobra un papel preponderante ante el florecimiento de la técnica, puesto que ésta le obliga a desarrollar sus potencialidades personales y a desplegar todos los "haceres" propios de su profesión: Liderar, participar, construir, producir, dinamizar, entre otros. 


\section{FUENTES}

\section{ARCHIVO SUTATENZA}

ACCIÓN CULTURAL POPULAR. (1977): Principios y fundamentos teóricos. Guía introductoria al conocimiento de ACPO. Bogotá, Andes, Archivo Sutatenza.

. (1979) Sus principios y medios de acción. Consideraciones Teológicas y Sociológicas. Cuarta Edición. Bogotá, Andes. Archivo Sutatenza.

SABOGAL José Ramón. Las Escuelas Radiofónicas, en Escuelas Radiofónicas Acción Cultural Popular VARGAZ, Carlos. s. p. i. Archivo Sutatenza.

SALCEDO GUARÍN José Joaquín. Auxiliares inmediatos, en Boletín de programas para las Escuelas Radiofónicas y para los hogares BERNAL ESCOBAR, Luis. (Director) (1955) colombianos No 20 (abril de 1955); Sutatenza: s. n. Archivo Sutatenza.

(1956): Normas especiales para los auxiliares inmediatos. ACPO Escuelas Radiofónicas. Sutatenza Boyacá Colombia. Bogotá, Pío X. Archivo Sutatenza. . (1957): Las Escuelas Radiofónicas y su labor de 1954 a 1957. Informe de la dirección general de Acción Cultural Popular - Escuelas Radiofónicas a la II Asamblea General de la institución. Archivo Sutatenza.

(1957) Introducción, en Orientaciones para dirigentes campesinos de Escuelas Radiofónicas CASTRO, Siervo Tulio. (Coordinador). Instituto Masculino, Sutatenza, Mimeografiado. Archivo Sutatenza.

Las Cartillas un elemento de acción y un medio de comunicación de Acción Cultural Popular. Legajo: Documentos de Consulta para la historia de Acción Cultural Popular. Documento (3) s. f. Archivo Sutatenza. MANUSCRITO para artículos sobre ACPO. Para el periódico 'El Tiempo' (Sin más datos). Archivo Sutatenza.

SOLARTE, José. (1954: Carta enviada desde Chenkayb Santa Ana Nariño, en Boletín de programas para las escuelas radiofónicas y los hogares colombianos. No. 12. Agosto Radio Sutatenza. s. p. i. Archivo Sutatenza.

\section{PERIODICO}

PERIÓDICO EL CAMPESINO. Número 1. Junio 29 de 1958; No. 4. Julio 20 de 1958; No. 8. Agosto 17 de 1958. No. 9. Agosto 24 de 1958; Número 10. Agosto 31 de 1958.; Número 12. Septiembre 14 de 1958; Número 33. Febrero 8 de 1959; Número 37. Marzo 8 de 1959; Número 55. Julio 12 de 1959; Número 73. Noviembre 15 de 1959; No. 85. Febrero 14 de 1960; No. 98. Mayo 15 de 1960; No 102. Junio 12 de 1960; No. 114. Septiembre 4 de 1960; No. 120. Octubre 16 de 1960; No. 129. Diciembre 18 de 1960. Archivo Sutatenza.

\section{SELECCIÓN BIBLIOGRÁFICA}

BERNALALARCON Hernando. (1994): ACPO Una idea con semilla de futuro. Escrito a raíz de la Muerte de Monseñor Salcedo. 
BRUMBERG Stephan. (1978): Los medios masivos de comunicación al servicio del desarrollo rural colombiano, en Teoría y aplicación en el caso de Acción Cultural. .

MORGAN Robert; MUHLMAN Liliana y MASONER Paúl. (1980): Evaluación de sistemas de comunicación educativa. Bogotá, Andes.

SALCEDO GUARIN, José Joaquín. (1994): Sin producir riqueza no se acaba la pobreza. Bogotá, Violeta.

SALCEDO GUARÍN, José Joaquín; BERNALALARCO, Hernando; IGLESIAS, Nohora Inés. (1990): América latina la revolución de la esperanza, Bogotá, Violeta.

SARMIENTO MORENO, Luis Abrahán. (2005): Pensamiento educativo de Monseñor José Joaquín Salcedo Guarín. Tesis de Maestría en Historia. Universidad Pedagógica y Tecnológica de Colombia (UPTC).

SARMIENTO MORENO, Luis Abrahán. (2009): ACPO, una experiencia educativa: desarrollo integral de la humanidad, Bogotá, Universidad Nacional Abierta y a Distancia (UNAD)

TORRES, Camilo y CORREDOR, Berta. (1961): Las escuelas radiofónicas de Sutatenza. Colombia. Universidad Nacional. Centro de investigaciones sociales serie socioeconómica No. 2. Bogotá.

ZALAMEA Luis. (1994): Un Quijote Visionario, Bogotá, Jorge Plazas, Presencia.

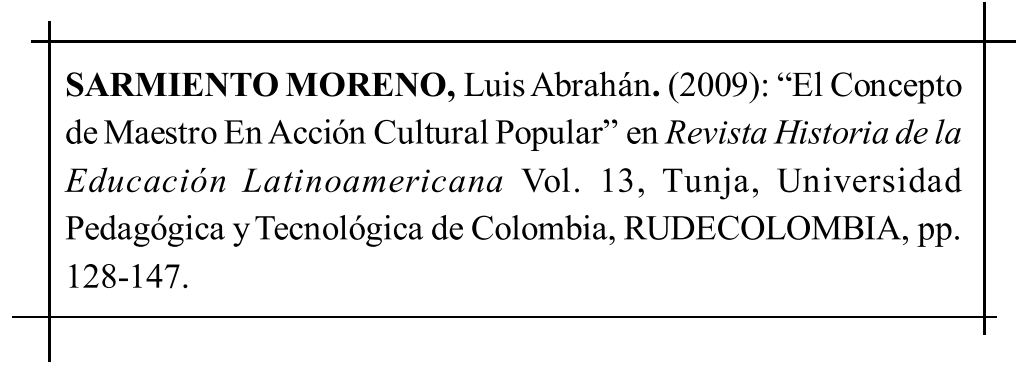

Rhela. Vol. 13. Año 2009, pp. $128-147$ 